Brit. J. industr. Med., 1959, 16, 200.

\title{
DERMATITIS IN THE SOUTH WALES MINING INDUSTRY: A REPORT OF A SURVEY OF TWO COLLIERIES
}

\author{
BY \\ BRYAN F. MATTHEWS* \\ From the Welsh National School of Medicine, Cardiff
}

(RECEIVED FOR PUBLICATION SEPTEMBER 29, 1958)

A survey to determine the prevalence of dermatitis in collieries and to investigate the aetiology of the condition has been carried out in South Wales.

Two collieries were chosen because of a marked variation between them in the incidence of claims for dermatitis compensation. The method was to examine the entire colliery populations and to submit the cases found to detailed study.

The populations consisted of all miners on the colliery pay-rolls on the day the survey began. Of both populations practically $100 \%$ were examined.

The cases were classified as occupational and non-occupational, and a third group was reserved for doubtful cases possibly related to occupation. The prevalence of occupational dermatitis was almost the same in the two collieries. The prevalence of non-occupational dermatitis was also similar in the two collieries. The incidence of claims for benefit does not therefore appear to reflect the true prevalence of the disease. A correlation between the contrasting claims rates and variation in the severity of occupational dermatitis in the two collieries was established.

Occupational dermatitis most commonly developed on the lower limbs; this tendency was greatest in coal-face workers. The special distribution of the rash corresponded to the areas most exposed to frictional damage at work.

This report presents the results of a survey of two collieries in which the main objectives were to measure the prevalence of dermatitis, and to investigate the aetiology of the disease.

The reason for investigating two collieries must be given. The measurement of prevalence in one colliery is to some extent an end in itself, but by establishing differences in prevalence in two, clues about the aetiology of dermatitis might be furnished with greater readiness.

\section{Choice of Collieries}

In planning an investigation into a disease with a relatively low prevalence the collieries selected must provide a reasonable hope of obtaining differences which are significant. Therefore a search was made for two collieries in which there was evidence that the prevalence of dermatitis could be expected to be high in one and low in the other.

A miner who contracts dermatitis which he con-

*This work was undertaken while the author held a National Coal Board Research Fellowship in dermatology.

Present address: Department of Physiology, University of Aberdeen tends is due to his employment may under the National Insurance (Industrial Injuries) Acts claim benefit. The claim that his incapacity is due to a prescribed industrial disease is made at the time a first medical certificate is received. This form is sent to the local insurance officer, who notifies the colliery at which the claimant is employed. The total of claims recorded at the colliery is published monthly and includes claims lodged by men with first attacks as well as by those with recurrences of dermatitis.

Since the number of claims in individual collieries offered a guide to the prevalence in them of dermatitis, the selection of suitable collieries was primarily based on an examination of these records.

A short list of eight neighbouring collieries was first made. These collieries were chosen because they had in common two features which, it was realized, would render the actual surveys more easily possible. First, each contained a stable labour force of approximately 1,000 , and secondly, they all had pit-head baths and medical centres.

The average number of claims in the eight 
collieries on the short list for the 18-month period preceding the surveys was 24.0 per thousand employed. Since the highest value was 39.0 in one colliery and the lowest 15.8 in another, these collieries, hereafter referred to as " high claim" colliery and "low claim " colliery respectively, were therefore the two selected for the present investigation.

It must be stressed that while it was appreciated that the number of claims for dermatitis compensation in the eight short-listed collieries might be considerably influenced by differing diagnostic standards among the medical practitioners responsible, there was no evidence of serious variation among the practitioners concerned with the claims arising in the two collieries finally selected.

\section{Detailed Objectives}

The detailed objectives were (1) to examine for evidence of dermatitis as large a percentage of the two colliery populations as possible. In dealing with a disease of relatively low prevalence it was important in surveying two populations each of the order of 1,000 workmen to examine them all. (2) To measure the real prevalence of dermatitis in the two collieries. Though emphasis was placed on the measurement of the prevalence of occupational (miner's) dermatitis, other forms of dermatitis unrelated to occupation were to be expected and their prevalence was measured. (3) To investigate the aetiology of occupational dermatitis in miners. In non-mining industries occupational dermatitis is primarily an exogenically determined condition. In miners the skin is constantly exposed to a variety of external physical hazards. Chief among these are frictional damage from dust and maceration by water and sweat. The third objective, therefore, was to investigate in miners the role of these factors in the aetiology of occupational dermatitis, and the problem was faced in two ways.

(a) Should the prevalence of occupational dermatitis as measured in the two surveys vary significantly and confirm the contrasting incidence of the claims for dermatitis compensation, then a careful comparison of environmental conditions below ground in both collieries might identify those factors primarily responsible for the condition. As the surveys showed a closely similar prevalence of occupational dermatitis in the two collieries (see Results), the aetiology was not investigated in this way.

(b) If external physical factors are the main cause of miner's dermatitis, then it follows that the highest prevalence would be expected in workmen most exposed to these hazards. This theory could be tested in the populations surveyed by contrasting the prevalence in workmen below ground with that measured in surface workers.

Among manual workers in an engineering factory, Squire, Cruickshank, and Topley (1950) found that hands and forearms, the sites most exposed to injury, were most commonly affected by skin disease. If it were found that in mineworkers also dermatitis developed most frequently in those anatomical areas most exposed to the action of external physical agents, the aetiological significance of these factors would be strengthened.

\section{Descriptive Background}

The two collieries chosen for the investigation are situated in the county of Glamorgan. Both stand in small, secluded, rural valleys about 10 miles apart. "High claim" colliery workmen come mainly from a moderately large mining town one mile away, while those employed at " low claim " colliery live in neighbouring villages.

The main " coaling" or " day" shift provides work for two-thirds of the total personnel in both collieries, the " afternoon" and " night" shifts employing the remainder in approximately equal numbers. Using similar methods and at equal depths of 1,800 feet, machine-cut and hand-loaded steam coal (volatile matter, 13-16\%) and bituminous coal (volatile matter, 23-26\%) are extracted at " high claim " and " low claim " collieries respectively. The average height of the seams worked in " high claim " colliery is $4 \mathrm{ft}$., in "low claim" colliery $5 \mathrm{ft}$., and the suppression of dust at source in all working faces is efficient.

The gradients of temperature to which miners are exposed while travelling to and from their various places of work underground were measured in the two collieries. In the September that the underground atmospheric environment was studied, " high claim " colliery pit bottom (" downcast") dry-bulb temperature was $60^{\circ} \mathrm{F}$. and "low claim" colliery $57^{\circ} \mathrm{F}$. In the first colliery the temperatures at the coalfaces varied between $70^{\circ} \mathrm{F}$. and $74^{\circ} \mathrm{F}$., while in the second they ranged from $67^{\circ} \mathrm{F}$. to $74^{\circ} \mathrm{F}$.

The effective temperature index which combines the three characteristics of an environment, namely, dry-bulb and wet-bulb temperatures, and the rate of air movement, was also measured in the two collieries. In travelling from " high claim " colliery pit-bottom to the various coalfaces, increases of from $14^{\circ} \mathrm{F}$. to $20^{\circ} \mathrm{F}$. in effective temperature were experienced, while in "low claim" colliery the corresponding increases were from $12^{\circ} \mathrm{F}$. to $22^{\circ} \mathrm{F}$.

Both collieries have pit-head baths and under the same roof a medical centre in the charge of a state registered nurse. 


\section{The Defined Colliery Populations}

The two populations consisted of all miners on the colliery pay-rolls except those absent from work for more than 12 months. An index giving the name, colliery registration number, age, and occupation of each workman was prepared from this source at both collieries, the final defined population being the one that existed on the day the survey began.

The two populations are compared in Fig. 1, and their composition in terms of broad work categories is shown in Table 1.

TABLE 1

\section{DEFINED COLLIERY POPULATIONS ANALYSED BY} OCCUPATION

\begin{tabular}{|c|c|c|c|c|c|c|}
\hline \multirow[b]{2}{*}{ Colliery } & \multirow{2}{*}{$\begin{array}{c}\text { Total } \\
\text { Popula- } \\
\text { tion }\end{array}$} & \multicolumn{4}{|c|}{ Underground Workmen } & \multirow{2}{*}{$\begin{array}{c}\text { Surface } \\
\text { Work- } \\
\text { men }\end{array}$} \\
\hline & & Colliers & $\begin{array}{c}\text { Other } \\
\text { Face- } \\
\text { workers }\end{array}$ & $\begin{array}{c}\text { Else- } \\
\text { where }\end{array}$ & Total & \\
\hline " High ," & 1,017 & 190 & 295 & 325 & 810 & 207 \\
\hline $\begin{array}{l}\text { "Low } \\
\text { claim " }\end{array}$ & 1,074 & 208 & 288 & 406 & 902 & 172 \\
\hline
\end{tabular}

General Methods of Work

" High claim" colliery was surveyed between August and December, 1954, and " low claim " colliery between February and June, 1955.

Lectures and informal talks with the Colliery Consultative Committee members explaining the scheme were started about a fortnight before the actual surveys. In addition, verbal and written propaganda was widely distributed throughout the collieries.

The actual surveying was done in two stages.

Screening for Dermatitis.-The object of this stage was to identify miners affected with dermatitis. To do this it was necessary to examine stripped and clean all members of the defined populations. This stage, therefore, was mainly carried out in the pit-head baths which at both collieries were used by more than $80 \%$ of miners.

In the baths each workman has two lockers, one for street clothes, the other for work clothes. Both "clean" and "dirty" lockers are arranged in 14 bays each containing 72 lockers. Every miner was examined for evidence of dermatitis beside his "clean" locker, generally after he had completed his shift and was about to dress for home after bathing. The name and colliery registration number of each man was recorded on a cyclostyled form, together with the results of the cutaneous inspection. The whole procedure occupied about three minutes. The names of those examined were then removed from the population index. A fresh bay was examined daily, and when the last was completed, approximately $75 \%$ of the defined populations had been screened for the presence of dermatitis.

To facilitate this stage, the busiest of the surveys, it was necessary to adopt a daily programme to account for the three workshifts. Miners completing the day shift were mainly examined between 2 and 3.30 p.m., those completing the afternoon shift betwen 10 and

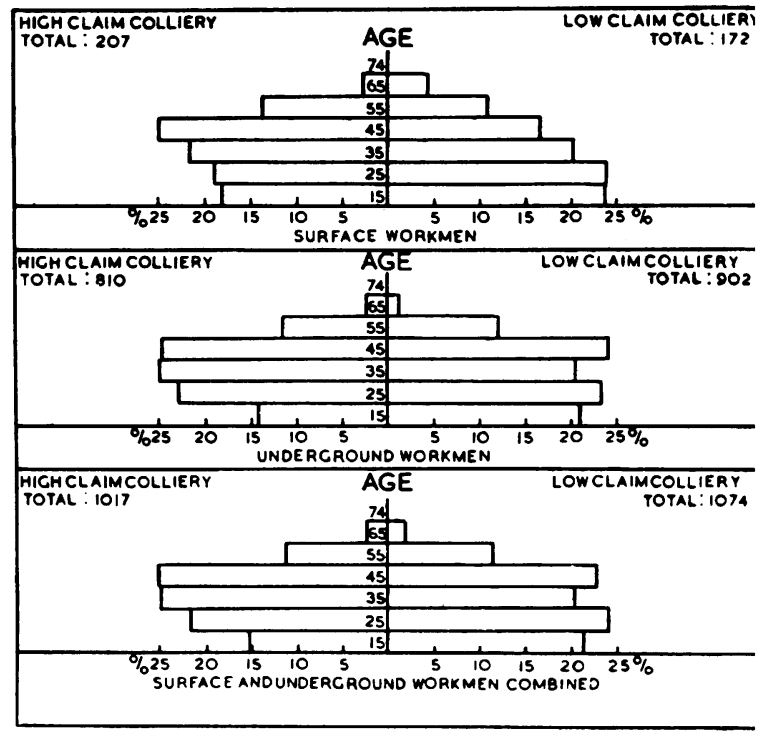

Fig. 1.-Defined colliery population analysed by age.

11 p.m., and night shift workers between 6 and 7 a.m. As the largest volume of work coincided with the conclusion of the day shift, the burden was eased by screening a proportion in the mornings before the start of the shift.

Approximately $20 \%$ of miners in both collieries bathed at home. These men, together with a few who were overlooked in the pit-head baths, were examined, before they started work, in the doctor's room at the colliery medical centre. By arrangement with the management, surface men engaged in clean work were often examined during the course of their shifts. Finally, a small minority were visited at their homes or in hospital.

Special arrangements were made to examine members of the populations terminating employment during the surveys. Through the cooperation of the management these workmen attended the medical centre for interview before their discharge from the colliery.

Irrespective of duration or morphology, the presence of dermatitis admitted a miner to the second stage of the survey.

Special Interview and Evaluation.-Miners with any skin disease detected at the preliminary screening were asked to attend the colliery medical centre. At this second interview of between 15 and 30 minutes it was first necessary to decide whether the rash each miner presented was significant for the purpose of measuring prevalence. Except where there was a history of past dermatitis, the existing rash was considered significant only when it had run a course of not less than seven days. In practice few cases-three in "high claim" colliery, five in " low claim" colliery-were inadmissible for this reason.

Diagnostic Criteria.- It is customary to classify dermatitis according to aetiology. In this survey of 
working miners, the cases of dermatitis found by the preliminary screening were divided in the first instance into two broad groups: occupational dermatitis, in which the physical environment in mining was considered to be the chief aetiological factor, and nonoccupational dermatitis, in which factors independent of mining were of greater importance.

(1) Occupational Dermatitis.-It must be stressed that while it was realized that in epidemiological surveys it is essential that the findings of different observers should be comparable, it was nevertheless difficult in the present investigation to arrive at satisfactory criteria on which to base the diagnosis of occupational dermatitis. Specific risks to the skin in non-mining industries are well known, and accurate diagnostic standards incorporating the added objective evidence of patch-testing are readily furnished. In miners, on the other hand, the natural history of occupational dermatitis is not yet clear, and therefore in the present investigation the diagnosis was assessed on subjective evidence alone.

The diagnosis was based upon a characteristic history of a rash, generally pruritic, first developing during employment as a miner, with evidence of recovery or improvement after withdrawal from the causative environment, with or without relapse or recurrence on returning to it. The cases which satisfied these criteria were then divided into the following three groups:

(a) Traumatic (non-specific) eczematous dermatitis; (b) contact sensitization dermatitis resulting from personal allergy to some external contact at work; (c) eczematous dermatitis, arising from aggravation by occupation of a predisposing constitutional eczema.

(2) Non-occupational Dermatitis.-Cases of dermatitis not conforming to the foregoing definition were classed as non-occupational dermatitis, and grouped further according to the specific diagnosis.

In miners it was to be expected that difficulty in excluding an occupational factor would arise. A third group was therefore reserved for cases of dermatitis of doubtful aetiology but in which it was possible that occupational factors played a contributory part in causation.

Groups Studied.-Seventy-one miners in " high claim " colliery and 73 in " low claim " colliery were interviewed and examined at this stage of the survey. Of these, 29 at each colliery were considered to be cases of occupational dermatitis and they form the principal groups studied in this report.

The cause was in doubt in 22 cases of dermatitis in " high claim" colliery and in 23 cases in "low claim" colliery. Because of this uncertainty it was considered unwise to draw detailed conclusions from a study of these groups, and the results presented for them are correspondingly less important.

Dermatitis assigned to the non-occupational group was represented by 20 cases in " high claim" colliery and 21 in "low claim" colliery. The cases in these groups were classified according to the specific diagnosis, but in both collieries the final numbers in each class were too small to permit detailed analysis.
Results

The Populations Examined.-Practically $100 \%$ of both populations were examined (99.8\% " high claim " colliery; 99.9\% " low claim" colliery). Of those miners not examined, one in each colliery died before an interview was arranged, and during the " high claim" colliery survey two men, one with a hemiparesis and the other with abdominal carcinomatosis, were not examined.

Most of the examinations were made on the colliery premises $(96.3 \%$, " high claim" colliery; $97.3 \%$, "low claim" colliery). The rest were conducted either in the home or hospital, and it was found that fewer home visits to absentees were necessary in surveying " low claim " colliery. It was easier for the ambulant sick in this colliery to attend the medical centre for examination since their homes were generally nearby. Most " high claim " colliery workmen, on the other hand, lived at a greater distance from their work, and therefore it was usually more convenient to visit an absentee at his home. Six mineworkers were examined in hospital during the two surveys.

Prevalence of Occupational Dermatitis.-Table 2 shows the prevalence of occupational dermatitis in the populations surveyed, and also compares the

TABLE 2

PREVALENCE OF OCCUPATIONAL DERMATITIS IN POPULATIONS SURVEYED, ACCORDING TO THREE PRINCIPAL CLINICAL TYPES

\begin{tabular}{c|c|c|c}
\hline Colliery & \multicolumn{2}{|c|}{$\begin{array}{c}\text { High Claim } \\
\text { (Pop. surveyed, 1,014) }\end{array}$} & $\begin{array}{c}\text { Low Claim } \\
\text { (Pop. surveyed, 1,073) }\end{array}$ \\
\hline Clinical type & No. & No. \\
\hline $\begin{array}{c}\text { Traumatic eczematous } \\
\text { dermatitis }\end{array}$ & $27 \quad(2 \cdot 7 \%)$ & 27 & $(2 \cdot 5 \%)$ \\
$\begin{array}{c}\text { Contact sensitization } \\
\text { dermatitis }\end{array}$ & - & 1 & \\
$\begin{array}{c}\text { Aggravation of con- } \\
\text { stitutional eczema }\end{array}$ & 2 & 1 \\
\hline
\end{tabular}

prevalence of the three principal types of the condition. The most striking feature is the close similarity of the prevalence in the two colliery populations. Traumatic eczematous dermatitis, quantitatively similar in the two collieries, predominates over contact sensitization dermatitis and constitutional eczema materially aggravated by occupation, which together form a very small part of the total prevalence. Hodgson (1955) pointed out that specific hazards to the skin in the mining industry are few, and in a series of 404 Welsh miners found a corresponding paucity of cases of occupational dermatitis resulting from sensitivity to rubber and other chemicals, or to oil, greases, and alkali. Similarly, among the miners with occupational dermatitis in the two populations now surveyed, only one was considered to be a case of specific sensitization 
TABLE 3

PREVALENCE OF OCCUPATIONAL DERMATITIS AMONG THE SURFACE AND UNDERGROUND WORKERS EXAMINED

\begin{tabular}{|c|c|c|c|c|c|c|c|c|}
\hline \multirow{2}{*}{ Colliery } & \multicolumn{2}{|c|}{ Coalface Workers } & \multicolumn{2}{|c|}{$\begin{array}{l}\text { Men Employed Elsewhere } \\
\text { below Ground }\end{array}$} & \multicolumn{2}{|c|}{ Surface Workers } & \multicolumn{2}{|c|}{ Total } \\
\hline & $\begin{array}{l}\text { No. } \\
\text { Examined }\end{array}$ & No. of Cases & $\begin{array}{c}\text { No. } \\
\text { Examined }\end{array}$ & No. of Cases & $\begin{array}{l}\text { No. } \\
\text { Examined }\end{array}$ & No. of Cases & $\begin{array}{l}\text { No. } \\
\text { Examined }\end{array}$ & No. of Cases \\
\hline $\begin{array}{l}\text { “ High claim ", } \\
\text { "Low claim " }\end{array}$ & $\begin{array}{l}485 \\
496\end{array}$ & $\begin{array}{l}13(2 \cdot 7 \%) \\
14(2.8 \%)\end{array}$ & $\begin{array}{l}322 \\
405\end{array}$ & $\begin{array}{l}14(4.4 \%) \\
13(3.2 \%)\end{array}$ & $\begin{array}{l}207 \\
172\end{array}$ & $2(1 \%)$ & $\begin{array}{l}1,014 \\
1,073\end{array}$ & $\begin{array}{l}29(2.9 \%) \\
29(2.7 \%)\end{array}$ \\
\hline
\end{tabular}

(patch test positive) dermatitis, the result of contact with rubber at work.

Occupational dermatitis of the type resulting from aggravation of a constitutional eczema was found in three miners among the populations examined; moderately severe seborrhoeic dermatitis was the underlying predisposing disorder common to all three.

Relationship with Occupation.-The colliery populations examined were divided into three broad occupational groups: coalface workers, miners employed elsewhere below ground, and surface workers. The prevalence of occupational dermatitis among these three groups is shown in Table 3. The prevalence in the miners employed below ground and away from the coalface appears slightly higher than that in the faceworkers. Unfortunately the number of cases in the two groups is small, and the observed difference is not significant. The surface workers were less commonly affected by occupational dermatitis. In each colliery, the difference between the prevalence in surface workers and that in workers below ground is barely statistically significant, but when the figures in the two collieries are combined the results, while not conclusive, are at least suggestive. It is probable that the risk of occupational dermatitis is greatest below ground, where physical hazards to the skin are more frequent.

Age at Onset of First Attack.-An analysis in terms of age at the time of the first attack is shown in Table $\mathbf{4}$ for the workmen below ground with occupational dermatitis. As there was no significant

TABLE 4

PERCENTAGE DISTRIBUTION OF CASES ACCORDING TO AGE AT TIME OF ONSET OF FIRST ATTACK IN UNDER-

\begin{tabular}{c|c|c}
\hline \multirow{2}{*}{$\begin{array}{c}\text { Age } \\
\text { (years) }\end{array}$} & “ High Claim " Colliery & " Low Claim " Colliery \\
\cline { 2 - 3 } & No. of Cases & No. of Cases \\
\hline 15 & $1(4 \%)$ & $3(11 \%)$ \\
25 & $2(7 \%)$ & $4(15 \%)$ \\
35 & $14(52 \%)$ & $7(26 \%)$ \\
45 & $6(22 \%)$ & $10(37 \%)$ \\
$55-64$ & $4(15 \%)$ & $3(11 \%)$ \\
\hline
\end{tabular}

variation in prevalence between coalface workers and men employed below ground away from the face, the cases of occupational dermatitis in the two groups are treated together. Moreover, as the actual age at the time of onset of the first attack was often in doubt, and also because of the small numbers involved, the cases are grouped in 10-year age groups. It will be seen that most cases of occupational dermatitis first developed in the age groups 35-44 and 45-54, these groups together accounting for $74 \%$ and $63 \%$ of the total cases in the two collieries. This confirms the observation of Rook and Hodgson (1954) that dermatitis in coal-miners principally develops in the two decades between 40 and 60.

Chief Sites of Onset in First Attack. - The relative frequency with which lesions first appeared on different parts of the body in the underground workers with occupational dermatitis is shown in Table 5. Because of the small numbers the cases

TABLE 5

CHIEF SITES OF ONSET OF FIRST ATTACK OF DERMATITIS IN COALFACE WORKERS AND MEN EMPLOYED ELSEWHERE BELOW GROUND

\begin{tabular}{l|c|c}
\hline \multicolumn{1}{c|}{ Chief Site of Onset } & $\begin{array}{c}\text { Coalface } \\
\text { Workers }\end{array}$ & $\begin{array}{c}\text { Men Employed } \\
\text { Elsewhere } \\
\text { below Ground }\end{array}$ \\
\cline { 2 - 3 } & No. & No. \\
\hline Dorsa feet and ankles & $11(41 \%)$ & $7(26 \%)$ \\
Tower legs & $6(22 \%)$ & $6(22 \%)$ \\
Thighs & $5(18 \%)$ & 0 \\
Necks and forearms & $4(15 \%)$ & $10(37 \%)$ \\
\hline
\end{tabular}

at both collieries have been combined. When lesions appeared in the first attack simultaneously at more than one site, the part most affected was recorded as the chief site of onset. The following tentative suggestions are made: (1) Occupational dermatitis in the first attack most commonly develops on the lower limbs, particularly in the region of the feet and ankles. (2) Among coalface workers these sites are more frequently affected than in men employed away from the face. (3) The reverse relationship holds for the frequency with which dermatitis develops on the hands and forearms in the two occupational groups. Hodgson (1955) reported a similar preponderance of origin on the lower limbs in a series of miners. The external physical factors 
responsible for the precipitation of dermatitis may exert their main influence on these areas. The place and nature of employment below ground also appear to influence the part of the body initially affected.

Duration of Exposure.-Table 6 compares the approximate duration of underground employment up to the time of onset of the first attack in workers below ground in the two collieries. Again because

TABLE 6

DURATION OF EXPERIENCE BELOW GROUND AT ONSET OF FIRST ATTACK IN UNDERGROUND WORKERS WITH OCCUPATIONAL DERMATITIS

\begin{tabular}{c|c|c}
\hline $\begin{array}{c}\text { Total Experience } \\
\text { below Ground (years) }\end{array}$ & $\begin{array}{c}\text { High Clain " } \\
\text { Colliery }\end{array}$ & $\begin{array}{c}\text { "Low Claim " } \\
\text { Colliery }\end{array}$ \\
\hline $0-$ & $1(4 \%)$ & $4(15 \%)$ \\
$10-$ & $4(15 \%)$ & $5(18 \%)$ \\
$20-$ & $11(41 \%)$ & $8(30 \%)$ \\
$30-$ & $7(26 \%)$ & $8(30 \%)$ \\
$40-$ & $2(7 \%)$ & $2(7 \%)$ \\
$50+$ & $2(7 \%)$ & 0 \\
\hline
\end{tabular}

of the small numbers involved, the cases in coalface workers and in workmen employed elsewhere underground have been combined for each colliery. The most striking feature is the long period at work which usually preceded the development of dermatitis. Eighty-one per cent (" high claim" colliery) and $67 \%$ (" low claim" colliery) were exposed for 20 years or more before the first appearance of the disease. For all miners affected the mean duration of employment was 27 and 24 years respectively in the two collieries, a latent period which is greater than the average of 15 years (in 59 colliery workers) reported by Sneddon (1951).

Chronicity and Incapacity.-The duration of the present attack, as measured at the time of examination, is shown in Table 7. The results illustrate the considerable chronicity of occupational dermatitis; in both collieries $40 \%$ of cases had persisted for more than 12 months. Cases of short duration are few. It may be concluded that equally in the two collieries the disease was generally persistent and often protracted.

TABLE 7

DURATION OF PRESENT ATTACK OF OCCUPATIONAL DERMATITIS

\begin{tabular}{|c|c|c|}
\hline \multirow{2}{*}{ Duration } & “ $\underset{\text { Colliery }}{\text { High Claim " }}$ & $\begin{array}{l}\text { "Low Claim " } \\
\text { Colliery }\end{array}$ \\
\hline & No. & No. \\
\hline $\begin{array}{c}\text { Less than } 1 \text { month } \\
1-3 \text { months } \\
3-6 \text { months } \\
6-9 \text { months } \\
9-12 \text { months } \\
1-2 \text { years } \\
2-5 \text { years } \\
5 \text { years }\end{array}$ & $\begin{array}{l}3(11 \%) \\
3(11 \%) \\
6(22 \%) \\
1(4 \%) \\
3(11 \%) \\
4(15 \%) \\
4(15 \%) \\
3(11 \%)\end{array}$ & $\begin{array}{l}1(4 \%) \\
4(15 \%) \\
3(11 \%) \\
6(22 \%) \\
2(7 \%) \\
5(19 \%) \\
2(7 \%) \\
4(15 \%)\end{array}$ \\
\hline
\end{tabular}

It must be stressed that most cases were studied at a single interview. Therefore, in the absence of a follow-up examination it was often difficult to assess the severity of the present attack on clinical grounds alone. As the present attack was often a repetition of a past attack, an alternative method of measuring the severity was obtained by combining the loss of work resulting from all attacks. Table 8 contrasts the total absence from work sustained by the two groups of workmen in past and present attacks of occupational dermatitis. The following differences in

TABLE 8

TOTAL ABSENCE FROM WORK ON ACCOUNT OF PAST AND PRESENT OCCUPATIONAL DERMATITIS

\begin{tabular}{|c|c|c|}
\hline \multirow{2}{*}{ Duration of Absence } & " High Claim $"$ & "Low Claim " \\
\hline & No. & No. \\
\hline $\begin{array}{l}\text { Nil } \\
\text { Less than } 1 \text { month } \\
1-3 \text { months } \\
3-6 \text { months } \\
6-12 \text { months } \\
1-2 \text { years } \\
\text { 2+ years }\end{array}$ & $\begin{array}{l}7(26 \%) \\
3(11 \%) \\
6(22 \%) \\
3(11 \%) \\
5(19 \%) \\
1(4 \%) \\
2(7 \%)\end{array}$ & $\begin{aligned} 14 & (52 \%) \\
6 & (22 \%) \\
1 & (3 \%) \\
3 & (11 \%) \\
1 & (4 \%) \\
1 & (4 \%) \\
1 & (4 \%)\end{aligned}$ \\
\hline
\end{tabular}

the record of absence are apparent. (1) Attendance at work was more frequently interrupted among the miners with occupational dermatitis in " high claim " colliery, where working time was lost in $74 \%$ of cases compared with $48 \%$ in " low claim" colliery. (2) The frequency with which serious loss of work was sustained was also greater in "high claim" colliery, $30 \%$ of those affected losing more than six months, compared with the corresponding figure of $12 \%$ in " low claim" colliery. These differences reflect the tendency for more severe occupational dermatitis to occur among the miners in "high claim " colliery.

Further support for this observation is given by comparing the dermatitis certification rates in the two groups of workmen for the five-year period preceding the surveys. Thus 19 of the 27 miners with occupational dermatitis in "high claim" colliery were granted compensation, and together these workmen accounted for a total of 46 separate certifications. In "low claim " colliery, on the other hand, seven out of the 27 miners affected were compensated, and the total number of certifications among them was 19 .

Non-occupational Dermatitis.-Table 9 shows the prevalence of non-occupational dermatitis among the populations surveyed. Hypostatic eczema was inevitably aggravated by trauma at work; in one case local injury initiated the condition. Foot powders and antihistamine cream accounted for four cases of contact sensitization dermatitis; penicillin tulle was incriminated in a further case, while 
TABLE 9

PREVALENCE OF NON-OCCUPATIONAL DERMATITIS IN POPULATIONS SURVEYED ACCORDING TO CLINICAL TYPE

\begin{tabular}{c|c|c}
\hline Colliery & $\begin{array}{c}\text { “" High Claim” } \\
\text { (Pop. surveyed, 1,014) }\end{array}$ & $\begin{array}{c}\text { “ Low Claim” } \\
\text { (Pop. surveyed, 1,073) }\end{array}$ \\
\hline Clinical Type & No. & No. \\
\hline $\begin{array}{l}\text { Hypostatic eczema } \\
\text { Besnier's prurigo }\end{array}$ & $7(0.7 \%)$ & $4(0.3 \%)$ \\
$\begin{array}{l}\text { Contact sensitization } \\
\text { dermatitis }\end{array}$ & 2 & 2 \\
$\begin{array}{l}\text { Seborrhoeic dermatitis } \\
\text { Infective eczema }\end{array}$ & $6(0.6 \%)$ & 9 \\
Pompholyx of hands & 2 & 1 \\
and feet & 1 & 1 \\
\hline Total.. & $20(2.0 \%)$ & $21(2.0 \%)$ \\
\hline
\end{tabular}

sensitization to nickel was the probable cause in an official who kept a small metal tape measure in his trouser pocket. Infective eczema consisted in each case of unilateral otitis externa with local eczematization of the pinna and cheek.

Dermatitis Possibly Related to Occupation.-While the aetiology of the cases in this group could not be established, it was possible that occupational factors played a contributory part in their causation. Compared with occupational dermatitis they differed in that the history was short and the dermatitis localized to one place on the body. From a study of the cases two main observations were made:

Relationship with Occupation.-Table 10 shows tion in " high claim" colliery, where six out of the 22 cases had received compensation in the past compared with two of the 23 in "low claim" colliery.

\section{Discussion}

This work demonstrated that by the use of suitable methods it is possible to examine for evidence of skin disease the entire population of a colliery, a result which made possible the accurate measurement of the amount of dermatitis at the time of the survey. That this was achieved at both collieries is important, since the main objective was to compare the actual prevalence of dermatitis in each of the two populations.

As regards the results, the most important finding is the close similarity of the prevalence of dermatitis in the two collieries. This is quite unlike the outcome expected from examining the claims for dermatitis compensation, and it can be concluded that in the two collieries the rate at which claims were lodged does not reflect the real prevalence of the disease. The higher rate among the miners in " high claim " colliery is explained by the observation that the cases of occupational dermatitis were more severe than those in " low claim" colliery. As a result loss of work was more common, and as a claim for benefit was usually made at the beginning of each period of unemployment, the number of

TABLE 10

PREVALENCE OF LOCALIZED DERMATITIS, POSSIBLY OCCUPATIONAL, IN SURFACE AND BELOW GROUND WORKERS EXAMINED

\begin{tabular}{l|c|c|c|c|c|c|c|}
\hline \multirow{2}{*}{ Colliery } & \multicolumn{2}{|c|}{ Surface Workers } & \multicolumn{2}{c|}{ Below Ground Workers } & \multicolumn{2}{c}{ Total } \\
\cline { 2 - 6 } & No. Examined & No. of Cases & No. Examined & No. of Cases & No. Examined & No. of Cases \\
\hline “ High claim" & 207 & $12(5.8 \%)$ & 807 & $10(1 \cdot 2 \%)$ & 1,014 & $22(2.2 \%)$ \\
\hline “Low claim" & 172 & $9(5 \cdot 2 \%)$ & 901 & $14(1.6 \%)$ & 1.073 & $23(2.1 \%)$ \\
\hline
\end{tabular}

the prevalence of the localized type of dermatitis in which the cause was uncertain in the surface and below ground workers at the two collieries. The prevalence among the surface workers was more than three times the rate in the workers below ground. No satisfactory reason to account for this marked difference could be found, but it may be significant that, of the total surface workmen affected, seven had previously worked below ground.

Absence from Work.-Compared with the occupational dermatitis group, this type of dermatitis caused little loss of work. Though the duration was never greater than two months, seven of the miners affected in " high claim" colliery compared with three in "low claim" colliery lost work. This difference, while smaller than that observed among the cases of occupational dermatitis, is similarly correlated with a higher rate of dermatitis certifica- claims was correspondingly greater. There is an alternative explanation for the observed disparity between prevalence and claims which might apply to both collieries but more particularly to " high claim " colliery where the difference is greatest and the disease more severe. It is possible that a first attack or recurrence causes a claimant to leave the mining industry, and in these circumstances the estimates of prevalence as measured in the present investigation would be less than those based on claims for compensation. That this explanation, however, applies to neither colliery is shown by the fact that not a single instance was recorded where a claimant left the industry as the result of dermatitis, either during the surveys or, so far as could be ascertained from the colliery medical records, during the 18-month period preceding the surveys.

From the point of view of investigating the causes 
of occupational dermatitis, the results are less striking; the number of cases for detailed study was small in both colliery surveys. The most significant clue is the tendency for the rash to be localized on the lower limbs, particularly in the region of the ankles, and on the dorsa of the feet. It suggests that mechanical trauma is the main factor responsible. This conclusion is supported by the observation that in the two broad occupational groups working below ground the frequency with which the lower limbs are involved is greatest among those most exposed to trauma, namely, in workers at the coalface.

Frictional damage is the chief type of mechanical injury to which the skin is subjected in the mining industry. In faceworkers frictional damage can arise either from dust particles which collect in the boot top, and impregnate the socks and trousers, or from constant rubbing together of apposed surfaces through habitual kneeling or squatting at work. The manifestations of continued frictional wear and tear are not immediately obvious; a latent period of the order of 20 years precedes the first appearance of dermatitis. What determines the final breakdown of the skin and the development of the disease is as yet unknown. Repeated frictional damage is but one factor among several in the aetiology of miner's dermatitis, and in the present investigation it was not possible to examine the role of constitutional and psychological factors. The purely provocative role of an exogenous factor such as frictional damage is, however, emphasized by the relative infrequency with which miners develop dermatitis before they have been employed for at least 15 years. Constitutional factors, as yet poorly understood, determine the development and course of the disease. In the ageing miner, for example, vascular responsiveness and cell metabolism may be so altered that in the face of continued frictional wear and tear the skin surrenders to dermatitis.

The natural history of miner's dermatitis as illustrated by the cases studied in this report can be summarized as follows. It is a disease of moderately high prevalence which affects workmen in the fifth and sixth decades after 20 years or more of work below ground. It is characterized by a predilection for the lower limbs, and is primarily determined by mechanical trauma. While generally persistent and often protracted, the severity is variable.

I am grateful to Dr. Geoffrey Hodgson for his help and guidance, and I should like to record my gratitude to the management and men, and the nursing officers, of the two collieries. Without their cooperation this investigation would not have been possible.

\section{REFERENCES}

Hodgson, G. (1955). Brit. J. Derm., 67, 426.

Rook, A., and Hodgson, G. (1954). Personal communication. Sneddon, I. B. (1951). Trans. Ass. industr. med. Offrs, 1, 142.

Squire, J. R., Cruickshank, C. N. D., and Topley, E. (1950). Brit. med. Bull., 7, 28. 